\title{
COVID-19, the economic crisis, and the Beirut blast: what 2020 meant to the Lebanese health-care system
}

Georges Mjaess, ${ }^{1}$ Aya Karam, ${ }^{1}$ Roy Chebel, ${ }^{1}$ Georges Abi Tayeh ${ }^{1}$ and Fouad Aoun ${ }^{1}$

'Hotel-Dieu de France, University of Saint Joseph, Beirut, Lebanon. (Correspondence to: Georges Mjaess: gmjaess@gmail.com; georges.mjaess@net.usj.edu.lb)

Citation: Mjaess G; Karam A; Chebel R; Tayeh GA; Aoun F. COVID-19, the economic crisis, and the Beirut blast: what 2020 meant to the Lebanese healthcare system. East Mediterr Health J. 2021;27(6):535-537. https://doi.org/10.26719/2021.27.6.535

Received: 18/02/21; accepted: 23/03/21

Copyright (c) World Health Organization (WHO) 2021. Open Access. Some rights reserved. This work is available under the CC BY-NC-SA 3.0 IGO license (https://creativecommons.org/licenses/by-nc-sa/3.o/igo).

\section{Introduction}

Lebanon has faced numerous challenges in the last three decades that have greatly impacted its health-care system, which has been historically disjointed first by the civil war (1975-1990), and second by the arrival of significant numbers of Palestinian and Syrian and refugees (1). Although Lebanon has tried to absorb these systemic shocks and recover, its health system has continued its slow decline and highlighted by events in 2020 .

The fragility of health-care systems worldwide were demonstrated by the COVID-19 pandemic that emerged in 2020 (2). Protective measures that are essential to a health-care system (i.e. standardization of processes, analysis of adverse events, accreditation, etc.) are insufficient for handling unforeseen events (3). Lebanon suffered a hattrick of simultaneous events during 2020 - the economic crisis, the Beirut blast and the COVID-19 pandemic - which sorely tested its ability to orchestrate recovery efforts. These events have accelerated the slow demise of the Lebanese health-care system into a disastrous free fall.

\section{The economic crisis}

Lebanon is facing its worst economic crisis since the civil war. This was accompanied by a subsequent devaluation of the Lebanese currency against the US dollar and curbs on international transfers out of the country (4). Lebanese hospitals rely mostly on imported products, especially stents, prostheses and medical devices, yet importing such essential supplies was limited, translating into a huge financial burden on the health-care system and a lack of medical equipment (4). In reality, private hospitals provide the majority of Lebanon's health services. Although the government is supposed to refund them through the national social security and military funds, that fact is "private hospitals are owed US\$ 1.3 billion and received no government funds at all in 2019" (4). Health-care workers have suffered pay cuts, deficiencies in equipment supplies, and unemployment. Patients are often unable to afford medical services impacted by the economic crisis, with more than $40 \%$ of the Lebanese population now living below the poverty line, especially in underserved areas (5).

\section{The Beirut blast}

On 4 August 2020, the Beirut port was hit by one of the biggest explosions in its history (6). Regardless of the cause, the blast was devastating for the Lebanese healthcare system (7). Some 200 people died, 6000 were injured, and tens of thousands were made homeless (8). The World Health Organization (WHO) confirmed that the blast caused damage to more than half of Beirut's health infrastructure - three hospitals became non-functional, three were extensively damaged, 500 hospital bed equivalents were lost, and many primary care facilities destroyed (8) - limiting the health service functionality essential for the response and management of such a crisis (9). Given the massive flow of patients during such a short time frame, hospitals used up two months' stock of medical supplies within days of the blast (10). Economic loss and physical damage were estimated to be US\$ 8 billion according to the World Bank (8).

\section{COVID-19 pandemic}

From the first documented case in Lebanon (21 February 2020) until July 2020, COVID-19 cases were reportedly few in number, especially after a lockdown that was implemented by the Lebanese authorities (11), and the systematic test and trace for symptomatic individuals as per WHO's recommendations (12). This, along with the limited number of public places and transportation services in Lebanon, helped contain the spread of the disease and Lebanon stood out as one of the leading countries in controlling the pandemic. Nevertheless, this reassuring state of affairs was short-lived. The number of cases started to gradually increase from July for various reasons, namely the opening of borders with no central quarantine programme in place; and decreasing public compliance with government public health directions.

The response to the Beirut blast was the first weakening in controlling the COVID-19 pandemic. The urgent situation meant a huge number of patients required medical services all at the same time. Nearly all patients arrived wearing no masks due to their injuries and all were confined together in emergency departments. Thus, it could be said that the blast also destroyed the initial success Lebanon achieved in mitigating the spread of COVID-19. A substantial and unsurprising rise in the 
number of positive cases was witnessed after 4 August (Figure 1), from a maximum of 100 daily cases before the event, to over 300 daily cases and seven deaths just one week after the blast. This first wave continued to reach a peak of circa 2000 cases by the end of October $2020-220 \%$ rise in cases as per the International Rescue Committee (13) - before a gradual decrease in reported numbers.

The second destabilizing factor for the health-care system and its response to COVID-19 was the economic crisis. The Lebanese government had taken the decision not to undergo a lockdown during Christmas and New Year holidays, and retail outlets as well as restaurants remained open, despite the worrying number of COVID-19 cases. The result was a dramatic surge in positive tests and reached circa 6000 cases by mid-January 2021 (Figure 1).

These two devastating waves of COVID-19 infections crippled the Lebanese health-care system and shifted emphasis towards preparing public hospitals to receive COVID-19 patients. Moreover, diverting governmental funds has depleted primary health-care centres' resources, threatening the permanence of their basic services. Lebanese hospitals have not prepared emergency risk management plans for crises such as epidemics (12). As a result, many private hospitals were drawn into the response and established COVID-19 care centres, while putting all elective surgeries on hold. Such steps placed significant economic hardship on private hospitals, which primarily rely on elective surgeries in order to maintain their financial viability, and so adding to the burden of both the economic crisis and the Beirut blast.

This resulting deterioration in the health-care system, as well as its precarious financial state, have led numerous health-care professionals to leave the country and seek employment overseas, primarily the Gulf States, Europe and the United States of America. This is a serious workforce problem adding to the already fragile health system and undermines Lebanon's reputation as the leading country in the Middle East for health-care expertise and facilities, renowned for its medical tourism.

\section{Conclusion}

The after-effects of this series of events on the Lebanese health-care system have meant it is on the verge of collapse. Is there a possibility the system will endure and be able to orchestrate recovery efforts? And if yes, would this be achievable within the current political environment? Any progress to health-service sustainability requires that lessons be learned from other countries in restructuring the basics of the health system, in order to develop effective crises management plans. It is only through planning for the unexpected that a country stands a chance of surviving the public health crises that Lebanon has been unfortunate enough to suffer.

Figure 1 Daily new COVID-19 cases in Lebanon divided into three phases, 2020

\section{Daily new COVID cases}

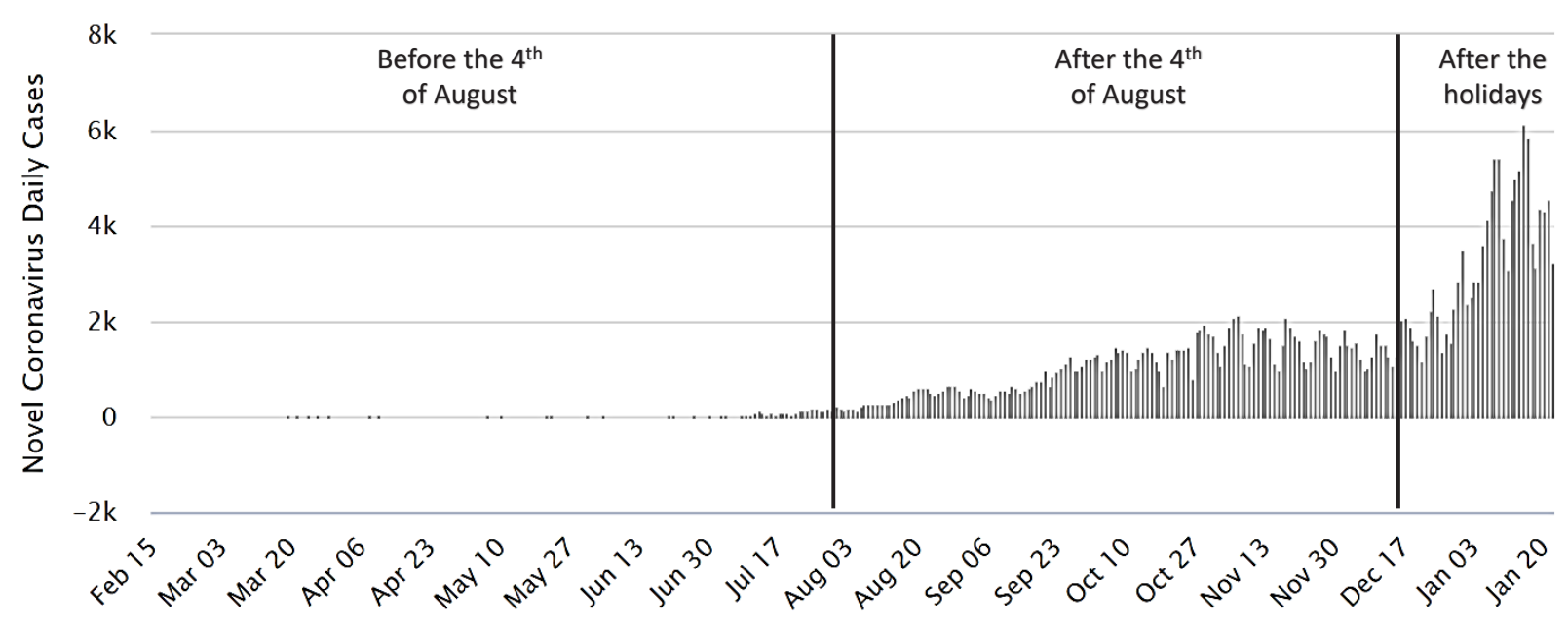




\section{References}

1. Santoro A, McKee M. Governing the Lebanese health system: strengthening the national response to the burden of Syrian refugees. East Mediterr Health J. 2017;23(6):449-452. https://doi.org/10.26719/23.6.449

2. Clay-Williams R, Rapport F, Braithwaite J. The Australian health system response to COVID-19 from a resilient health care perspective: what have we learned? Public Health Res Pract. 2020 Dec 9;30(4).

3. Braithwaite J, Wears RL, Hollnagel E. Resilient health care: turning patient safety on its head. Int Soc Qual Health Care. 2015 Oct;27(5):418-20.

4. Devi S. Economic crisis hits Lebanese health care. Lancet. 2020 Feb 22;395(10224):548.

5. United Nations Economic and Social Commission for Western Asia (ESCWA). Poverty in Lebanon: Solidarity is vital to address the impact of multiple overlapping shocks. Beirut: ESCWA; 2020;3. (https://www.unescwa.org/sites/www.unescwa.org/ files/20-00268_pb15_beirut-explosion-rising-poverty-en.pdf).

6. Guglielmi G. Why Beirut's ammonium nitrate blast was so devastating. Nature. 2020 Aug 10. doi: 10.1038/d41586-020-02361-x

7. Abdallah W, Khalil K, Najib B, Kassis N, Atallah D. Beirut blast: creating our expectations through heartbreak. Future Sci OA. 2020;Nov 9;7(2):FSO653.

8. Abouzeid M, Habib RR, Jabbour S, Mokdad AH, Nuwayhid I. Lebanon's humanitarian crisis escalates after the Beirut blast. Lancet. 2020;Oct 31;396(10260):1380-2.

9. World Health Organzation. Lebanon explosion: update for partners. Geneva: World Health Organization; 18 Aug 2020 (https:// www.who.int/docs/default-source/documents/emergencies/who-leb-partners-update-18-august-2020.pdf?sfvrsn=820c93ad_4

10. Landry MD, Alameddine M, Jesus TS, Sassine S, Koueik E, Raman SR. BMC health services research title: the 2020 blast in the port of Beirut: can the Lebanese health system "build back better"? BMC Health Serv Res. 2020;20(1):1040. (https://europepmc. org/article/med/33183285).

11. Republic of Lebanon Ministry of Public Health. Novel Coronavirus 2019. Beirut: Ministry of Public Health; 2019 (https://www. moph.gov.lb/en/Pages/2/24870/novel-coronavirus-2019).

12. Bizri AR, Khachfe HH, Fares MY, Musharrafieh U. COVID-19 pandemic: an insult over injury for Lebanon. J Community Health. 2020 Jul 13;1-7. doi: 10.1007/s10900-020-00884-y

13. International Rescue Committee. COVID-19 cases increase $220 \%$ in month since Beirut explosion. New York: International Rescue Committee; 2020. (https://www.rescue.org/press-release/covid-19-cases-increase-220-month-beirut-explosion). 